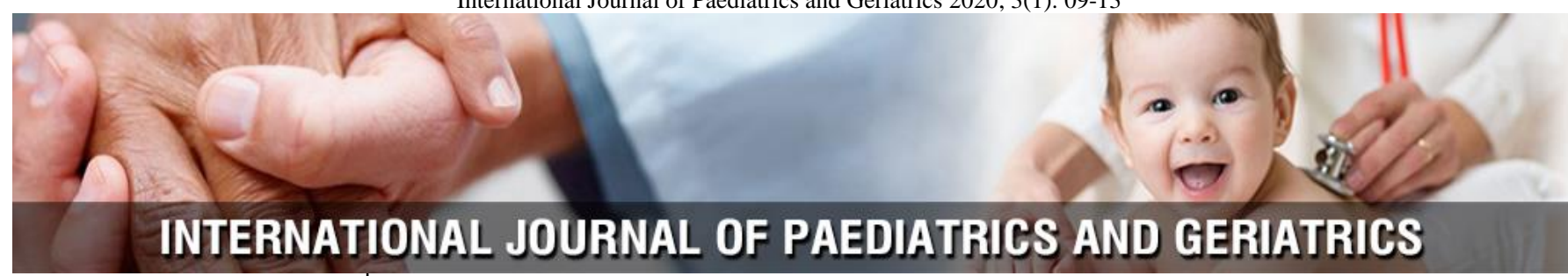

P-ISSN: 2664-3685

E-ISSN: $2664-3693$

www.paediatricjournal.com

IJPG 2020; 3(1): 09-13

Received: 06-11-2019

Accepted: 10-12-2019

Dr. Muddana Narasimha Rao Assistant Professor,

Department of Paediatrics,

Shadan Institute of Medical

Sciences, Hyderabad,

Telangana, India

Dr. Mohd Kashifuddin Hasan MD, Paediatrics, Shadan Institute of Medical Sciences, Hyderabad, Telangana, India

Dr. Mohd Safiuddin Hasan MD, Paediatrics, Shadan Institute of Medical Sciences, Hyderabad, Telangana, India

Corresponding Author: Dr. Mohd Kashifuddin Hasan MD, Paediatrics, Shadan Institute of Medical Sciences, Hyderabad, Telangana, India

\section{A study of common aeroallergens in children with wheeze-at a tertiary care centre}

\author{
Dr. Muddana Narasimha Rao, Dr. Mohd Kashifuddin Hasan and Dr. \\ Mohd Safiuddin Hasan
}

DOI: https://doi.org/10.33545/26643685.2020.v3.i1a.52

\begin{abstract}
Background: Wheezing is a highly frequent symptom in paediatric populations. An etiologic diagnostic is complex and becomes more difficult with younger children. For asthma, allergen exposure plays a fundamental role in sensitization, and subsequent acute and chronic symptoms Skin prick test (SPT) allows detection of sensitization safely and efficiently in all age-groups.

Aim and objectives: To assess the prevalence of sensitization to aeroallergens in a pediatric population with recurrent wheezing episodes using SPT.

Methodology: Cross-sectional observation study to study the type of allergic sensitivity in a pediatric population in Hyderabad.

Results: Children with recurrent (4 or more episodes of wheezing in the past year) ages between $2 \mathrm{yrs}$ to $10 \mathrm{yrs}$. The total number of the patients included in the study was 100 patients, $50(50 \%)$ male and $50(50 \%)$ with Mean Age $=6.15$ years. Out of the 50 male cases, $35(70 \%)$ had positive SPT to at least one of the aeroallergens and $15(30 \%)$ were negative for all aeroallergens tested. Out of the 50 female cases, 32(64\%) had a positive SPT to at least one of the aeroallergens and $18(36 \%)$ were negative for all aeroallergens. Out of 100 children, $67(67 \%)$ had positive SPT to at least one of the aeroallergens. $26(70.2 \%)$ of patients with positive tests were in the age group 5-7 years and $26(78.78 \%)$ were in the age group of 8-10 Yrs. Only $15(48.3 \%)$ were found in the age group 2-4 years. The highest prevalence of positive skin reaction was recorded for mite allergens among them Dermatophytosis pteronyssinus (80.5\%), D. Farinae (80.5\%), Bloomia (56.4\%), among Fungi group, Aspergillus fumigates (11.9\%) Alternaria alternate $(10.4 \%)$, Cladosporium herbarum $(2.9 \%)$ Cat, cockroach and pigeon showed positive in $(19.4 \%)(14.9 \%)$ and $(4.4 \%)$ of cases respectively. Allergy to indoor allergens was significantly higher than outdoor allergens (P-value $<0.0001$ ).

Conclusion: SPT is an effective way to determine aeroallergen with minimal expense \& greater selection of antigen. Specific allergen identification helps in implementing specific allergen preventive measures. Dust mites are the most common aeroallergen in all age groups. Among Dust Mites Dermatophagoides Farinae, Dermatophagoides pteronyssiuns \& Blomia are most common. Incidence of aero allergy in children with recurrent wheeze increases with age. Indoor allergens are more common than outdoor allergens.
\end{abstract}

Keywords: Wheezing, allergens, paediatric population, SPT, dust mites

\section{Introduction}

Wheezing is a frequent symptom in infants and children. Its major causes are respiratory infections and allergies. An allergy refers to a hypersensitivity reaction that occurs on reexposure to sensitizing allergen, usually a protein molecule, causing a release of inflammatory mediators.

Wheezing is a common problem worldwide and the most frequent causes of wheezing in preschool children are bronchiolitis and asthma ${ }^{[1-3]}$. Parents of infants with recurrent wheezing often ask the Pediatrician: "Will my children develop asthma?" This is a crucial question that involved also a clinician in the diagnostic and therapeutic attempts. Proper identification of children at risk of developing asthma at school age may predict long-term outcomes and improve treatment and preventive approach, but the possibility to identify these children at preschool age remains limited. The proportion of Indian school children suffering from bronchial asthma has increased to more than double in the last 10 years and has reached its highest level ever. The prevalence of childhood asthma in Hyderabad was $8.5 \%$. [4] There was a low prevalence of bronchial asthma (2.3-3.3\%) in the children surveyed in Lucknow ${ }^{[5]}$, North India, but in urban Delhi, the prevalence of bronchial asthma was $11.6 \%$ [6]. The prevalence of bronchial asthma in children from rural areas of Ludhiana and Punjab was $2.6 \%$ and $1 \%$, respectively. 
The rise in prevalence over time in Bangalore has been associated with environmental pollution, urbanization, and the change in the demography of the city. These factors might be responsible for inter-city variation in the prevalence of childhood bronchial asthma.

Among the children whoever reported wheeze, one-fourth of them confirmed to be suffering from bronchial asthma later in life. ${ }^{[7]}$ A study done on children from urban and rural areas in Tamil Nadu in the age group of 6-12 years showed the prevalence of wheeze to be $18 \%{ }^{[8]}$.

A major role is played by aero-allergens in the pathogenesis of respiratory allergic diseases, particularly asthma. Previous studies from different cities of India have identified airborne pollens, spores, mites and other particles responsible for allergy ${ }^{[9]}$, and observed incidence of allergic manifestations and positivity rates for various allergens on skin prick testing (SPT) ${ }^{[10]}$. The prevalence of allergic diseases may be different both inside and between countries. This difference is attributed to the level or a total load of aeroallergens. The prevalence of different aeroallergens has been determined in the studies conducted in other parts of the world. Different allergens play different roles depending on environmental conditions of each region, such as climate, population, and level of exposure [11] Identifying the aeroallergens of each region help prevent allergic diseases in an advisable time, while it is effective in selecting the type of allergy vaccine for appropriate treatment when prevention and medical treatment are not effective and allergy vaccines are required.

The present study was planned to identify these common allergens, probably responsible for inducing recurrent wheezing in subjects, as no study has been done in the recent past, in this central geographical part of the country, at Hyderabad and surrounding area.

\section{Materials and Methods \\ Design}

Cross-sectional observation study to study the type of allergic sensitivity in a paediatric population in Hyderabad

\section{Sample}

Children with recurrent ( 4 or more episodes of wheezing in past one year) ages between 2 yrs to $10 \mathrm{yrs}$

Sample Size: $\mathrm{n}=100$

\section{Inclusion criteria}

Frequent wheezers ( $>4$ episodes in past one year) in the age group of 2 to $10 \mathrm{yrs}$

\section{Exclusion criteria}

Dermatographism or any skin lesions was excluded during the physical examination before SPT.

Patients having SPT positive to one or more aeroallergens but negative to histamine control. Refusal of parents to give consent

\section{Methodology}

After a thorough medical history and physical examination, a written questionnaire was completed for each patient. Children with recurrent wheeze, who fall in inclusion criteria are subjected to skin prick tests for different aeroallergens listed below, the study was approved by the Ethics Committee of our hospital and all patients provided informed consent to participate in the study. In total 100 patients were included in the study if they met inclusion criteria and agreed to participate, data collected from SPT results are analyzed and most common aeroallergens causing allergic symptoms in patients visiting our OPD is studied

\section{Method}

Skin testing is done by the widely practiced skin prick test (SPT) According to European Guidelines ${ }^{[12]}$.

\section{Allergen extracts to be used}

- Mites (Dermatophagoides pteronyssinus, Dermatophagoides farina, Blomia tropicalis)

- Anemophilous fungi (Alternaria alternate, Cladosporium herbarum, Aspergillus fumigates)

- Epithelia of a dog (Canis familiaris)

- Epithelia of a cat (Felis domesticus)

- Epithelia of pigeon (Columba livia)

- Cockroach (Periplaneta americana)

- Parthenium grass (Parthenium hysterophorus)

- Bermuda grass (Cynodon dactylon)

\section{Statistical methods}

The data is entered and analyzed in Microsoft Excel 2010. For analysis, descriptive statistics used were percentage, mean and standard deviation (SD). Data presented in descriptive tables and analysis was done at a 95\% confidence interval (CI) using a Chi-Square test. A P value less than 0.05 was considered statistically significant. All the analysis was carried out using SPSS 16.0 and EPI Info 3.5.1.

\section{Results}

The total number of the patients included in the study was 100 patients, of the 50 [50\%] male and 50 [50\%] female. (Table-3) with Mean Age $=6.15$ years and $\mathrm{SD}=2.4$.

Table 1: Sex Wise Distribution

\begin{tabular}{|c|c|c|}
\hline & Frequency & Percent \\
\hline Male & 50 & 50 \\
\hline Female & 50 & 50 \\
\hline Total & 100 & 100.0 \\
\hline
\end{tabular}

The study group is divided into three age groups, 2-4yrs., 5$7 \mathrm{yrs}$ and 8-10 yrs. The frequency of each group is shown in table 2 .

Table 2: Age Distribution

\begin{tabular}{|c|c|c|}
\hline Age Groups & Frequency & Percent \\
\hline 2-4Yrs & 31 & 31 \\
\hline 5-7Yrs & 36 & 36 \\
\hline 8-10Yrs & 33 & 33 \\
\hline Total & 100 & 100.0 \\
\hline
\end{tabular}

Out of 100 children in the study, 67 children were found sensitive to at least one aeroallergen and 33 were negative for all aeroallergens association between positive skin prick test and wheezing is shown in Graph 1.

Out of the 50 male cases, $35(70 \%)$ had positive SPT to at least one of the aeroallergens and $15(30 \%)$ were negative for all aeroallergens tested. Out of the 50 female cases, $32(64 \%)$ had a positive SPT to at least one of the aeroallergens and 18(36\%) were negative for all aeroallergens. 
Table 3: Association of sex and allergen sensitization

\begin{tabular}{|c|c|c|}
\hline SPT & Male & Female \\
\hline Positive & 35 & 32 \\
\hline Negative & 15 & 18 \\
\hline P-Value & \multicolumn{2}{|c|}{0.6709} \\
\hline
\end{tabular}

Out of 100 children, 67 (67\%) had positive SPT to at least one of the aeroallergens. $26(70.2 \%)$ of patients with positive tests were in the age group 5-7 years and 26 $(78.78 \%)$ were in the age group of $8-10$ Yrs. Only 15 (48.3\%) were found in the age group 2-4 years (Table 4).

A statistically significant correlation is seen between age groups and sensitivity ( $\mathrm{p}$-value 0.025 ).

Table 4: Association of Skin Prick test with age group

\begin{tabular}{|c|c|c|c|}
\hline Age & Sensitivity Present & No Sensitivity & Total \\
\hline 2-4Yrs & $15(48.3 \%)$ & $16(51.7 \%)$ & $31(31 \%)$ \\
\hline 5-7Yrs & $26(70.2 \%)$ & $10(29.8 \%)$ & $36(36 \%)$ \\
\hline 8-10Yrs & $26(78.78 \%)$ & $7(21.22 \%)$ & $33(33 \%)$ \\
\hline Total & $67(67 \%)$ & $33(33 \%)$ & $100(100 \%)$ \\
\hline
\end{tabular}

The highest prevalence of positive skin reaction was recorded for mite allergens among them Dermatophytosis pteronyssinus $(80.5 \%)$, D. farinae $(80.5 \%)$, Bloomia (56.4\%), among Fungi group, Aspergillus fumigates $(11.9 \%)$ Alternaria alternate $(10.4 \%)$, Cladosporium herbarum $(2.9 \%)$ Cat, cockroach and pigeon showed positive in $(19.4 \%)(14.9 \%)$ and $(4.4 \%)$ of cases respectively. Among Pollen group Cynodon dactyl (8.9) \&
Parthenium hysterophorus (7.4)

The frequency of positive tests to an individual allergen is depicted in the table (8). In the studied population, the highest a prevalence of positive skin reactions was documented for the D. pteronyssinus and D. farinae with a frequency of $(80.5 \%)$ of cases, and the lowest for Dog (Canis familiaris) $(0 \%)$ of cases respectively.

Table 5: Skin sensitivity to allergens

\begin{tabular}{|c|c|c|c|c|c|}
\hline No & Allergen Group & Allergens & No of Patients & Percent & Percent of Cases \\
\hline 1 & \multirow{3}{*}{ Mites } & D. Farinae & 54 & 54 & $80.5 \%$ \\
\hline 2 & & D. Pteronyssinus & 54 & 54 & $80.5 \%$ \\
\hline 3 & & D. Bloomia & 46 & 46 & $68.6 \%$ \\
\hline 4 & \multirow{3}{*}{ Fungi } & Aspergillus Fumigatus & 8 & 8 & $11.9 \%$ \\
\hline 5 & & Alternaria Alternate & 7 & 7 & $10.4 \%$ \\
\hline 6 & & Cladosporium Herbarum & 2 & 2 & $2.9 \%$ \\
\hline 7 & \multirow{2}{*}{ Pollens } & Cayanodon Dactylon & 6 & 6 & $8.9 \%$ \\
\hline 8 & & Parthenium Hysterophorus & 5 & 5 & $7.4 \%$ \\
\hline 9 & \multirow{3}{*}{ Epithelia } & Cat Epithelia & 13 & 13 & $19.4 \%$ \\
\hline 10 & & Dog Epithelia & 0 & 0 & $0 \%$ \\
\hline 11 & & Pigeon & 3 & 3 & $4.4 \%$ \\
\hline 12 & Insects & Cockroach & 10 & 10 & $14.9 \%$ \\
\hline
\end{tabular}

Out of the 67 children with a positive skin prick test, 66 showed sensitivity to indoor allergens (dust mites, fungi, cockroach, cat) \& 10 showed sensitivity to the outdoor allergen (pollen, pigeon). The association between indoor allergens and wheezing is statistically significant (P-value $<0.0001)$.

Table 6: Association between indoor and outdoor allergens

\begin{tabular}{|c|c|c|}
\hline Allergen & Positive & Negative \\
\hline Indoor & 66 & 1 \\
\hline Outdoor & 10 & 57 \\
\hline
\end{tabular}

Chi square value $=95.3 \mathrm{p}$ value $<0.0001$

\section{Discussion}

Aeroallergens are the prominent causes of allergic symptoms in patients with recurrent wheeze. In this study, $67 \%$ of patients were sensitive to aeroallergen but $33 \%$ had negative skin prick tests. This negative reaction may be probably that the patients were sensitized to particular allergens that have not been tested in our study; or not identified yet; the local generation of $\operatorname{IgE}$ explains this group. ${ }^{[13]}$ This high percent of sensitization also was shown by the two studies in Iran which report $(81 \%)^{[14]},(63.2 \%)$ [15] of their patients had positive skin reactivity to aeroallergens, which were also comparable to $68 \%$ in
Farhoudi A et al., ${ }^{[16]}$ study. $89.2 \%$ in Shakurnia A et al. ${ }^{[17]}$. Mites were the most common aeroallergen in patients with allergic diseases in the current study. Which is similar to other Indian studies of Moitra et al. ${ }^{[18]}$. When compared to our study pollens are the most common cause of sensitization in Tehran [19], Tikrit ${ }^{[20]}$, Qazvin ${ }^{[21]}$. This difference also was expected since mites tend to require high humidity and moderate temperature to thrive, whereas pollens require a dry climate and a high temperature. In many humid countries, dust mites were the most important cause of sensitization in allergic children, because mites tend to require high humidity to thrive ${ }^{[22,23]}$. Surprisingly, mite allergens were also reported in hot and dry regions, like Kuwait ${ }^{[24]}$ and Sistine and Baluchistan Province of Iran ${ }^{[25]}$. It might be related as reported that the wide use of air conditioners which make good conditions for mites to grow and increase susceptibility to indoor allergens ${ }^{[14]}$.

Among mites, D.P had the highest rate of sensitization and D.F and bloomia were next in importance. In a similar study, house dust mites were reported to have the highest rate of sensitization among Malaysian asthmatic patients ${ }^{[26]}$ and patients with allergic rhinitis in Thailand, ${ }^{[27]}$ Singapore ${ }^{[28]}$ and Beijing [29]. Bloomia also showed a significant reaction in our study which is comparable to other studies Chew FT et al. ${ }^{[28]}$. Our study showed there is a rising trend 
in the sensitization pattern of bloomia which was not seen in other studies.

Among the fungi, in our study Aspergillus fumigatus (10.6\%) being the most common sensitizer followed by Alternaria Alternate and (7.4\%), penicillium species $(5.4 \%$,$) . similarly, Aspergillus fumigates had been identified$ as a major fungal allergen in the study of Prasad et al. ${ }^{[30]}$.

Results from the current study showed that $8.5 \%$ of patients had positive skin reactions to cockroach allergen. Farhoodi studied the sensitivity of asthmatics to cockroach allergens in children from 6 months to 12 years old and reported a $29 \%$ rate of positive skin tests in these children ${ }^{[31]}$. Results of a study in northern Iran have also reported the prevalence of sensitivity to cockroach allergen in patients with asthma, 12.7 percent ${ }^{[32]}$.

This study result had shown that there is less sensitivity to animal dander, in contrast, Western and European countries ${ }^{[19]}$ show a higher percent of sensitization because of the incidence of domestic pets in their homes more than our country.

In this study, according to the highest prevalence of allergies to mites, properly training of the patients about avoiding contact with these agents as the most important way to prevent and treat as well as informing about allergy symptoms, all are effective in prevention and reduction of the severity of symptoms in patients. Furthermore, using immunotherapy for desensitization to common allergens will have a significant effect on the symptoms to be completely disappeared.

The study showed a prevalence of positive skin prick tests of $70 \%$ in males and $64 \%$ in females. Thus it shows Boys had a slightly greater prevalence of any positive skin-test (70\% vs $64 \%)$, responses to house dust mite $(91.4 \% \%$ vs $100 \%)$. Gender difference is not statistically significant in an association of positive skin prick test and wheezing. Dust mites were the most common allergens in both genders.

Table 7: Association between sex and sensitivity

\begin{tabular}{|c|c|c|}
\hline SPT & Male & Female \\
\hline Positive & 35 & 32 \\
\hline Negative & 15 & 18 \\
\hline P-Value & \multicolumn{2}{|c|}{0.6709} \\
\hline
\end{tabular}

Sensitivity to aeroallergens increased significantly with age. The frequency of sensitization was $48.3 \%$ among children aged 2 years to 4 years $70.2 \%$ in the age group of 5-7 years and $78.78 \%$ in the age group of $8-10$ years. This is similar to the results of Pendino P, et al. Rosario [33]

The most common group of aeroallergens in each age group was found to be Dust Mites accounting for $100 \%$ of positive skin prick tests in the age group of 2-4 years, $88.88 \%$ of positive skin prick tests in the age group of 5-7 years and $92.3 \%$ of positive skin prick test in the age group of $8-10$ years.

Overall, only 13 patients (13\%) have positive pricks test to any pollen extract. Ligustrum lucidum accounts for $61.5 \%$ of total positivities (8 of 13). Grass mix and Platanus americana appear with 2 positivities each, and 1 for Ambrosia elatior. These results contrast with other studies in areas such as Virginia and the United States, where authors found high levels of sensitivity to pollen in young children. It shows a positive prick test in $29 \%$ of children aged 1 to 2 years, and it increases to $50 \%$ in those in the range of 3 to 4 years. ${ }^{[34]} \mathrm{A}$ greater number of pollinic seasons are likely required to sensitize to young children. The study showed an increased sensitivity to indoor allergens in the cases as out of the 67 children with a positive skin prick test, 66 showed sensitivity to indoor allergens (dust mites, fungi, cockroach, cat) \& 10 showed sensitivity to the outdoor allergen (pollen, pigeon). The association between indoor allergens and wheezing is statistically significant (P-value <0.0001). The indoor allergens accounted for $98.5 \%$ of the positive skin prick test whereas the outdoor allergens accounted for $14.9 \%$ of the positive skin prick tests.

The major indoor allergenic proteins that have been characterized are house dust mite allergens, cat antigens, dog dander antigens, mouse antigens, cockroach antigens, and certain fungal allergens.

\section{Conclusion}

Our result confirmed that mites are the main sensitizing aero-allergens among patients with recurrent wheeze in and around Hyderabad. Among mites Dermatophagoides Farinae, Dermatophagoides pteronyssinus and Bloomia are the most common aeroallergens. The SPT is an important test to know the sensitization of aeroallergen, which has a high sensitivity, low specificity, less expensive with minimal equipment and a greater selection of antigen. The sensitivity to aeroallergens increases with age. In children, the sensitivity to indoor allergens is more prevalent than sensitivity to outdoor allergens. Sensitivity to pollen was found in older children more than 5 years of age. Furthermore, this study may also help control or avoid allergens causing allergic disease.

\section{References}

1. Worldwide variations in the prevalence of Bronchial Asthma symptoms: International study of Bronchial Asthma and allergies in childhood (ISAAC). Eur Respir J. 1998; 12:315-35.

2. Reid J, Marciniuk DD, Cockcroft DW. Bronchial Asthma management in the emergency department. Can Respir J. 2000; 7:255-60

3. Gürkan F, Ece A, Haspolat K, Derman O, Bosnak M. Predictors for multiple hospital admissions in children withBronchial Asthma. Can Respir J. 2000; 7:163-6.

4. Prevalence of Allergic Rhinitis, Atopic Dermatitis, and Asthma among school children in Hyderabad, India Veerapaneni Vaishnavi, Jayaraj BS, Lokesh KS, Chaya SK, Vishnun Rao Veerapaneni, Amrutha Holla, Mahesh Pa. Journal of Allergy and Clinical Immunology. 139(2):AB20

5. Singh D, Sobti PC, Arora V, Soni RK. Epidemiological study of Bronchial Asthma in rural children. Indian $\mathrm{J}$ Community Med. 2002; 27:167-70.

6. Chhabra SK, Gupta CK, Chhabra P, Rajpal S. Prevalence of Bronchial Asthma in school children in Delhi. J Asthma. 1998; 35:291-6.

7. Paramesh H. Epidemiology of Bronchial Asthma in India. Indian J Pediatr. 2002; 69:309-12.

8. Chakravarthy S, Singh RB, Swaminathan S, Venkatesan P. Prevalence of Bronchial Asthma in urban and rural children in Tamil Nadu. Natl Med J India. 2002; 15:260-3.

9. Chhabra SK, Gupta CK, Rajpal S, Chhabra P. Prevalence of Bronchial Asthma in Indian Children. J Asthma. 1998; 25:73-82. 
10. Prasad R, Verma SK, Dua R, Kant S, Khushwah RAS, Agrawal SP. A study of skin sensitivity to various allergens by skin prick test in patients of nasobronchial allergy. Lung India. 2009; 26(3):70-73.

11. Singh AB, Kumar P. Aeroallergens in clinical practice of allergy in India. An overview. Ann Agric Environ Med, 10:131-136.

12. Position paper. Allergen standardization and skin tests. The European Academy of Allergology and Clinical Immunology. Allergy. 1993; 48(14):48-82.

13. Grossman J. One airway, one Disease: Chest 1997; 111(1):11-16.

14. Fereidouni M, Farid Hossini R, Jabbari Azad F, Ali Assarezadegan M, Varasteh A. Skin prick test reactivity to common aeroallergens among allergic rhinitis patients in Iran. Allergol Immunopathol. 2009; 37(2):73-9.

15. Behmanesh F, Shoja M, Khajedaluee M. Prevalence of aeroallergens in childhood asthma in Mashhad. Maced J Med Sci. 2010; 3(3):295-8.

16. Farhoudi A, Razavi A, Chavoshzadeh Z, Heidarzadeh M. Descriptive Study of 226 Patients with Allergic Rhinitis and Asthma. Iran J Allergy, Asthma Immunol. 2005; 4(2):99-101.

17. Shakurnia A, Assarehzadegan MA, Mozaffari AR. Prevalence of aeroallergens sensitivity in asthmatic patients from Ahvaz. Jentashapir J Heal res. 2012, 3-10.

18. Moitra S, Sen S, Datta A, Das S, Das P et al. Study of Allergenicity Spectrum to Aero Allergens by Skin Prick Testing. Austin J Allergy. 2014; 1(1):4.

19. Mohammadi K, Gharagozlou M, Movahedi M. A Single Center Study of Clinical and Paraclinical Aspects in Iranian Patients with Allergic Rhinitis. Iran j allergy asthma Immunol. 2008; 7:163-7.

20. Taha B, Abd AI, Saleh RI, Mohammed T, Aljubory H. A study of Skin prick test reactivity to common aeroallergens among patients with allergic rhinitis in Salahelden Governorate. Tikrit J pure Sci. 2011; 16(4):40-4.

21. Mahram M, Barikani A, Nejatian N. Allergy \& Therapy The Frequency of Common Allergens in Allergic Rhinitis among the Patients Referred to the Allergy Clinic of Qods Hospital Qazvin during 2007-2010. J Allergy Ther. 2013; 4(1):1-5.

22. Sporik R, Holgate ST, Platts-Mills TA, Cogswell JJ. Exposure to house-dust mite allergen (Der p) and the development of asthma in childhood. A prospective study. N Engl. J Med. 1990; 323(8):502-7.

23. Ontiveros CR, lopez SM, Cerino JR. Aeroallergens detected by skin prick test in children with respiratory allergy (asthma and rhinitis) from the south of Mexico City. Alergia Immunol Pediatr. 1995; 4:112-116.

24. Ezeamuzie CI, Thomson MS, Al-Ali S, Dowaisan A, Khan M, Hijazi Z. Asthma in the desert: spectrum of the sensitizing aeroallergens. Allergy. 2000; 55(2):15762.

25. Khazaei HA, Hashemi SR, Aghamohammadi A, Farhoudi F, Rezaei N. The study of type 1 allergy prevalence among people of South-East of Iran by skin prick test using common allergens. Iran $\mathbf{J}$ Allergy Asthma Immunol. 2003; 2(3):165-8.

26. Liam CK, Loo KL, Wong CM, Lim KH, Lee TC. Skin prick test reactivity to common aeroallergens in asthmatic patients with and without rhinitis.
Respirology. 2002; 7(4):345-50.

27. Pumhirun $\mathrm{P}$, Towiwat $\mathrm{P}$, Mahakit P. Aeroallergen sensitivity of Thai patients with allergic rhinitis. Asian Pac J Allergy Immunol. 1997; 15(4):183-5.

28. Chew FT, Lim SH, Goh DY, Lee BW. Sensitization to local dust-mite fauna in Singapore. Allergy. 1999; 54(11):1150-9.

29. Zhang YM, Zhang J, Liu SL, Zhang X, Yang SN, Gao J et al. Prevalence and associated risk factors of allergic rhinitis in preschool children in Beijing. Laryngoscope 2013, 28-35.

30. Prasad R, Verma S, Dua R, Kant S, Khushwah RA, Agrawal SP. Lung India. 2009; 26(3):70-73.

31. Farhoudi A, Pourpak M, Mesdaghi Z, Chavoshzadeh A, Kazemnejad A. The study of cockroach allergy in Iranian children with asthma. IJMS. 2002; 27(4):15660.

32. Ghaffari J, Khademloo M, Saffar M, Rafiei A, Masiha F. Hypersensitivity to House Dust Mite and Cockroach Is the Most Common Allergy in North of Iran. Iran. J Immunol. 2010; 7(4):22-27.

33. Pendino P, Agüero C, Cavagnero P, Lopez K, Kriunis I, Molinas J. Aeroallergen sensitization in wheezing children from rosario, Argentina. World Allergy Organ J. 2011; 4(10):159-63.

34. Ogershok PR, Warner DJ, Hogan MB, Wilson NW. Prevalence of pollen sensitization in younger children who have asthma. Allergy Asthma Proc. 2007; 28:654658 . 